\title{
Allelopathic activity of Acer negundo L. leaf litter as a vector of invasion species into plant communities
}

\author{
Anastasia A. Nikolaeva ${ }^{1 *}$, Elena V. Golosova ${ }^{1}$, Olga V. Shelepova ${ }^{2}$ \\ ${ }^{1}$ Nikitsky Botanical Garden - National Scientific Center of the Russian Academy of Sciences, \\ Moscow branch, 119991 Moscow, Russia \\ ${ }^{2}$ N.V. Tsitsin Main Botanical Garden of Russian Academy of Sciences, 127276 Moscow, Russia
}

\begin{abstract}
The article shows the results of the influence of different concentrations of allelochemicals of Acer negundo L. leaf litter, germination energy, absolute germination of seeds and plant growth. The seeds of Raphanus sativus L. and Avena sativa L. were used as model objects. Active substances contained in leaf litter A. negundo, have a selective inhibitory effect on the germination of seeds and the growth of seedlings of monocotyledonous and dicotyledonous plants. The allelopathic effect of the fall is not a limiting factor for the germination of seeds of herbaceous plants of the above-ground cover of the studied plantation.
\end{abstract}

\section{Introduction}

Occupying more and more new territories, invasive species in secondary habitats represent an important factor in the transformation of natural ecosystems. Often, the introduction of invasive species into communities leads to a decrease in the species diversity of indigenous communities or to the disappearance of some species.

Acer negundo L., an alien species from North America, actively inhabits the landscapes of Eurasia. For many regions of Russia this species is invasive. In Russia, in 18 out of 24 regions, this species is assigned to the group with the invasive status 1 (the most dangerous). Plant species from this group are actively introduced into natural and seminatural communities, change the appearance of ecosystems, disrupt successional relationships, act as edifiers and dominants. They form a significant area of single-species thickets, displace and (or) prevent the renewal of natural flora species [1, 2, 3, 4]. A number of authors believe that $A$. negundo has a negative impact on the formation of herbage in its sub-crown space. This is expressed in a decrease in alpha- and gamma- diversity [5], and in reduction in the projective cover. According to Gusev et al. [6], the projective cover of the grass tier under the crown of A. negundo is 30-40\%, and the species richness is 2-3 times less than in natural communities of the same age. At the same time, local forest species that are able to develop normally with a lack of illumination are being displaced from the subcrown space of $A$. negundo, which grows in an urban environment, and the herbaceous

\footnotetext{
*Corresponding author: hrenko@yandex.ru
} 
cover is mainly represented by synanthropic species [2]. All this leads to the depletion of the species composition of the herbage, and in some cases to the formation of deadcovered, low-ornamental areas with almost complete absence of herbage [7]. At the same time, there is evidence that more favorable conditions for the growth of native grasses are created under the canopy of $A$. negundo, and the germination of native grasses is not suppressed [8].

Often, invasive species enter into competitive relationships with local species and become the cause of impoverishment of the species composition of plant communities. One of the possible mechanisms of successful introduction is explained by allelopathic interactions, when an alien plant in one way or another secretes substances that suppress or, conversely, activate the vital activity of surrounding plants in the local phytocenosis. The phytotoxic effect of $A$. negundo has been convincingly shown in a number of works $[8,10$, $11,12]$. This effect can be caused by various secondary metabolites and does not always have the same negative effect on all plants in the community $[10,13,14]$. The chemical compounds of leaf litter have the most negative effect, to a lesser extent - secondary metabolites isolated from the roots [10]. The phytotoxic effect can manifest itself in different ways: it can affect the number of sprouted species, slow down the development of seedlings. Thus, according to the data of Yu. A. Eremenko [11] A. negundo belongs to the group of allelopathically highly active plants and has a high index of allelopathic activity. A number of studies devoted to the study of allelopathic properties of invasive species have shown that the properties of plant extracts from different biocenoses may differ [15]. Extracts from plants growing on disturbed biocenoses are often more toxic than extracts from plants from natural biotopes.

The purpose of this work was to determine the allelopathic effect of A. negundo leaf litter, selected on the territory of the N.V. Tsitsin Main Botanical Garden, on the germination energy, absolute germination and growth of monocotyledonous and dicotyledonous plants.

\section{Materials and Methods}

A. negundo leaf litter was collected in the autumn of 2020 on the territory of the forest zone of the GBS RAS (specially protected natural area). As test objects we used radish seeds Raphanus sativus L. (variety "Red with a white tip" of the company "Sedek") and oat seeds Avena sativa $\mathrm{L}$. (from a lawn mixture).

As a starting solution in the experiment, an aqueous extract was prepared from crushed leaves of natural drying in a ratio of $1: 10$. The extract was prepared in two versions: by infusing the ingredients for 5 and 24 hours. Further, solutions of concentrations of 1:25, 1:50 and 1:100 were obtained from the initial solution by dilution. The scheme of the experience is presented in Table 1.

Table 1. Scheme of the experience of evaluating the allelopathic effect of A. negundo leaf litter

\begin{tabular}{|c|c|c|c|}
\hline \multirow{2}{*}{$\begin{array}{c}\text { Series } 1 \\
\text { (infusion of leaf litter for } \\
5 \text { hours) }\end{array}$} & \multirow{2}{*}{$\begin{array}{c}\text { Series } 2 \\
\text { (infusion of leaf litter for } \\
24 \text { hours) }\end{array}$} & \multicolumn{2}{|c|}{$\begin{array}{c}\text { germination energy, absolute } \\
\text { germination and growth }\end{array}$} \\
\hline & & $\begin{array}{l}\text { Raphanus sativus } \\
\text { L. }\end{array}$ & Avena sativa $\mathrm{L}$ \\
\hline $\begin{array}{l}\text { I } 5 \text { h: water extract } \\
\text { solution } 1: 10\end{array}$ & $\begin{array}{l}\text { I 24h: water extract } \\
\text { solution } 1: 10\end{array}$ & \multirow{3}{*}{$\begin{array}{l}\text { Germination of } \\
\text { seeds in Petri } \\
\text { dishes on filter } \\
\text { paper, wetted } \\
\text { with a solution } \\
\text { for } 5 \text { days }\end{array}$} & \multirow{3}{*}{$\begin{array}{l}\text { Germination of } \\
\text { seeds in glasses } \\
\text { on filter paper } \\
\text { moistened with a } \\
\text { solution for } 14 \\
\text { days }\end{array}$} \\
\hline $\begin{array}{l}\text { II 5h: water extract } \\
\text { solution } 1: 25\end{array}$ & $\begin{array}{l}\text { II 24h: water extract } \\
\text { solution } 1: 25\end{array}$ & & \\
\hline $\begin{array}{l}\text { III 5h: water extract } \\
\text { solution } 1: 50\end{array}$ & $\begin{array}{l}\text { III 24h: water extract } \\
\text { solution } 1: 50\end{array}$ & & \\
\hline
\end{tabular}




\begin{tabular}{|l|l|l|}
\hline $\begin{array}{l}\text { IV } 5 \mathrm{~h}: \text { water extract } \\
\text { solution } 1: 100\end{array}$ & $\begin{array}{l}\text { IV 24h: water extract } \\
\text { solution 1:100 }\end{array}$ & \\
\cline { 1 - 2 } Control - distilled water & & \\
\hline
\end{tabular}

The seed germination energy was determined by the Grodzinsky method on radish seeds [10]. To do this, 50 radish seeds were placed in a Petri dish on filter paper moistened with $5 \mathrm{ml}$ of the test solution and left in a thermostat at a temperature of $+26{ }^{\circ} \mathrm{C}$ for $14-15$ hours. The number of germinated seeds was calculated when $50 \%$ of the seeds germinated on the control. Data on the germination of seeds in the experimental variants are expressed in $\%$ of the control. To determine the absolute germination, the germinated seeds were counted after 5 days. The experiment was carried out in a five-fold repetition.

To assess the test-objects growth, radish seeds were grown in Petri dishes (40 pcs each seeds per cup) on moistened filters for 5 days; the total amount of solution per cup was 9 $\mathrm{ml}$. Oat seeds (50 pieces per experiment) were grown on moistened filter paper in glasses for 14 days of weeks, the total amount of solution per experiment was $50 \mathrm{ml}$.

An indicator of the intensity of growth of radish plants in the experiment was the length of the hypocotal knee and root (in $\mathrm{cm}$ ). An indicator of the growth rate of oat plants was the length of the stem and root (in $\mathrm{cm}$ ).

\section{Results and Discussion}

In model experiments, the allelopathic properties of $A$. negundo leaf litter were evaluated. At the first stage of the experiment, the effect of a solution of water extract from leaf litter in various concentrations of secondary metabolites on the germination rate of radish seeds was measured (Fig. 1).

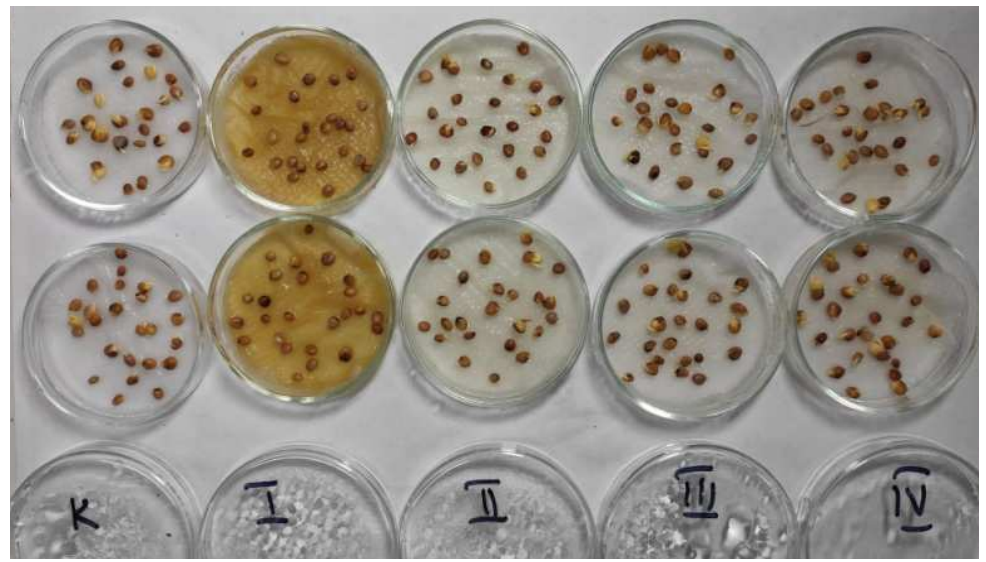

Fig. 1. Germination $\mathrm{f}$ radish seeds in solutions of different concentrations of extract from A. negundo leaf litter.

The initial solutions of water extracts (1:10) from A. negundo leaf litter of both series of experiments (5-hour and 24-hour infusion) had the maximum negative effect on the germination energy of radish seeds. Only $1 \%$ of the seeds from the 24-hour infusion experience (I $24 \mathrm{~h}$ ) and $4 \%$ from the 5-hour infusion experience (I $5 \mathrm{~h}$ ) sprouted (Fig. 2). Dilution of the initial solution also reduced the seed germination rate by 25 times - by 20 $28 \%$ compared to the control. The use of a more diluted solution (1:50) significantly reduced the germination rate only in the second series (24-hour infusion) of the experiment. All other variants of both series of experiments did not differ statistically from the control. In the second phase of the experiment (with the germination of $100 \%$ of radish seeds on 
the control), the initial solutions also had a negative effect on the energy of the germination of radish seeds: although the germination rate increased compared to the first phase of the experiment, it still remained very low compared to the control - 2 and $22 \%$ in the second (24-hour infusion) and the first series (5-hour infusion) of the experiment, respectively (Fig. 2). When comparing the germination rate of radish seeds using dilute solutions of 5-hour infusion, some stimulating effect of these solutions was found in comparison with the control. The use of dilute solutions of the second series (24-hour infusion) of the experiment practically did not affect the energy of seed germination.

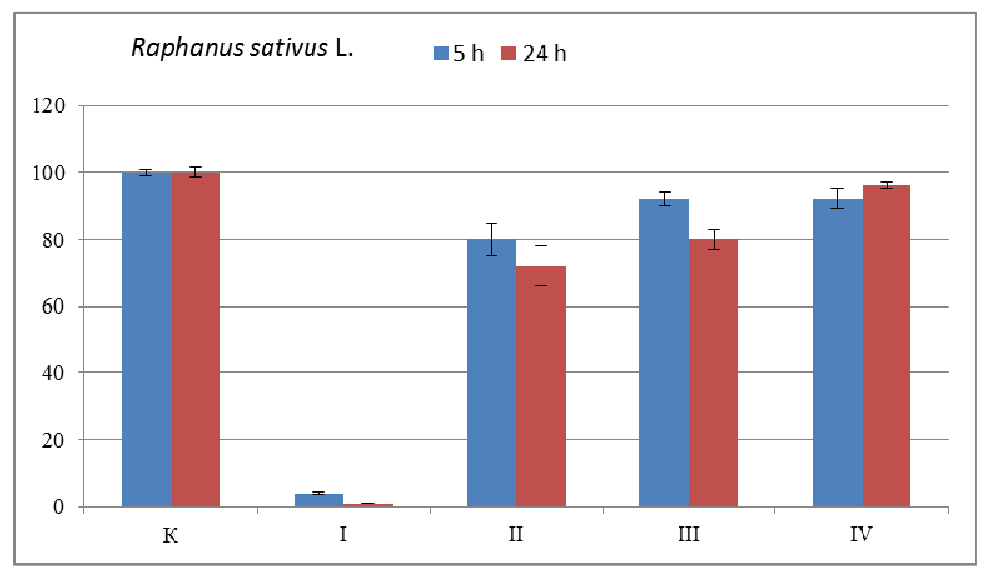

Fig. 2. The effect of solutions of water extract from A. negundo leaf litter on the germination energy of Raphanus sativus L. seeds: when using solutions of 5 and 24-hour infusion.

The experiment showed that extracts from A. negundo leaf litter have a selective inhibitory effect on the germination and growth of monocotyledonous and dicotyledonous plants. The maximum toxic effect of the water extract was noted on radish seeds. The germination capacity of radish seeds soaked in an initial solution of 1:10 in both series of experiments was $80 \%$ and $78 \%$ lower, respectively, compared to the control (Fig. 3). More dilute solutions did not have a noticeable effect on the germination of radish seeds. The effect of the stock solutions on the seeds of a monocotyledonous plant (A. sativa) was less toxic; the suppression of seed germination in both series (5 and 24-hour infusions) of the experiment was $14 \%$ lower than in the control. More dilute solutions also did not have a noticeable effect on the germination of A. sativa seeds.

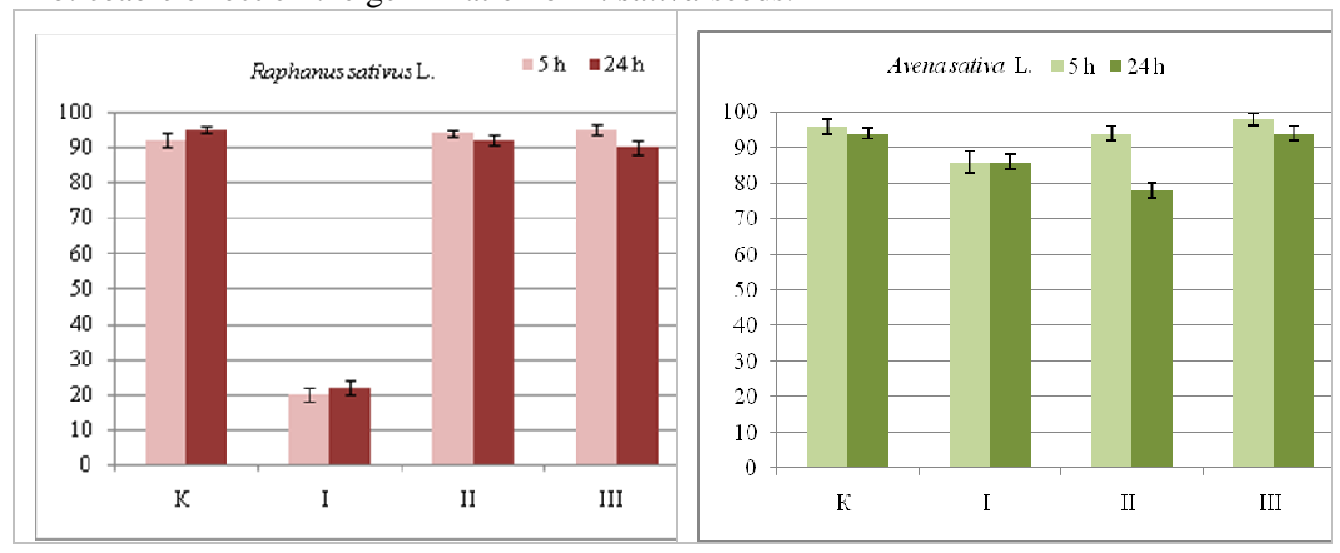

Fig. 3. The effect of solutions of aqueous extract from A. negundo leaf litter on the germination of seeds of Raphanus sativus L. and Avena sativa L. when using solutions of 5-hour and 24-hour 
infusion.

As a result of the experiment, it was found that solutions of concentrations 1:10 and 1:25 in both series of experiments (5-hours and 24-hours infusion) have a suppressive effect on the growth of the aerial part of plants in the case of $R$. sativus (dicotyledons): compared with the control was less from $20 \%$ to $98 \%$. At a concentration of 1:50 and 1:100, a clear stimulating effect of the solutions was noted: the length of the hypocotal knee compared to the control was greater from $7 \%$ to $24 \%$, respectively. At the same time, it was noted that the formed cotyledonous leaves opened completely and were 1.2-1.3 times larger than the control ones.

In the study of root growth, it was found that an extract with a concentration of 1:10 has a uniquely suppressing effect - the length of the roots is $78 \%$ and $88 \%$ less than in control plants (in the case of using solutions of 5-hous and 24-hours infusion, respectively). Lower concentrations of solutions have a stimulating effect on root growth. When using the solution of the first series (5-hour infusion) at concentrations of 1:25, 1:50 and 1:100, the length of the roots increases by an average of $36 \%$ compared to the control. When using solutions of the second series of experiments (24-hour infusion), the length of the roots of radish at the minimum concentration is comparable to the length of the root in the control, i.e. the stimulating effect was not observed.
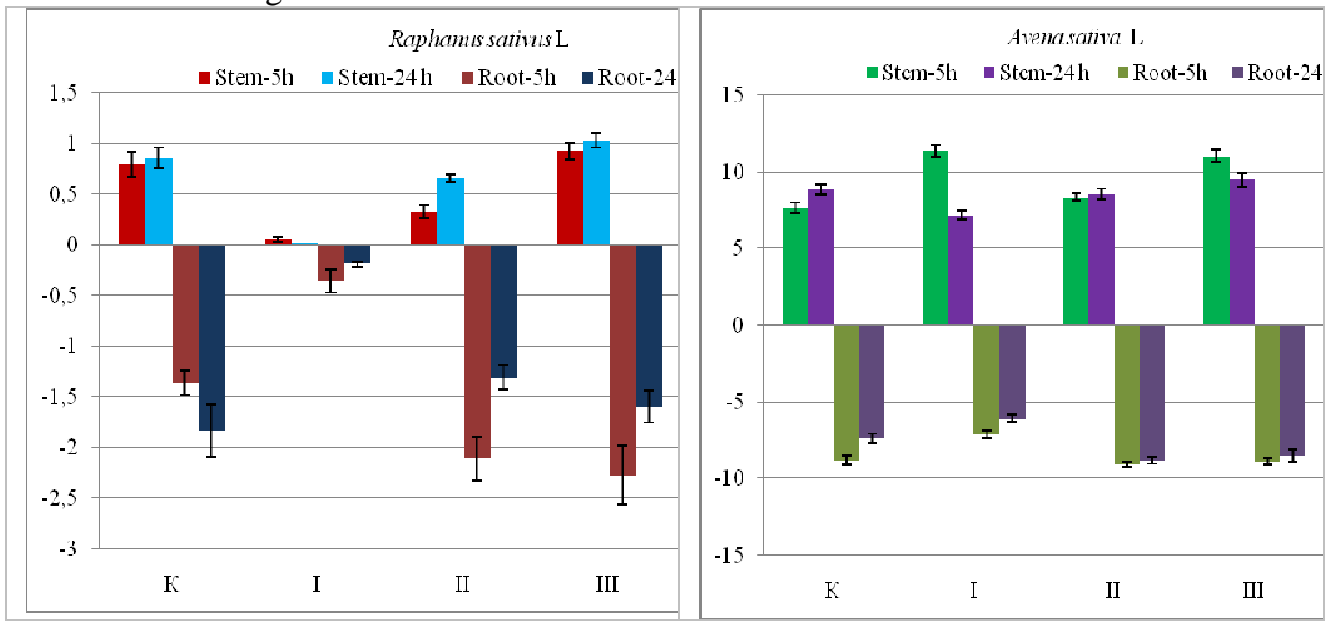

Fig. 4. Influence of aqueous extract solutions on the growth of Raphanus sativus L. and Avena sativa L.

When growing A.sativa in a series of experiments using a solution of a 5-hour infusion, stimulation of plant growth was observed in all variants. At the highest concentration of the solution (1:10), the maximum stimulating effect on the growth of the aboveground part of the plants was noted (the average stem length was $38 \%$ higher than in control plants), but the root length was $12 \%$ shorter than in the control (Fig.4). At other concentrations, the length of the stem and roots did not differ statistically significantly from the control.

In the second series of experiments (24-hour infusion), the inhibitory effect of a 1:10 solution was noted - the length of the stem and root by the end of the observations were 1.2 times less than that of the control plants (Fig. 4-5). In variant III (concentration 1:50), a slight stimulation of the growth of oat plants was observed: the length of the stem increased by 1.1 times, and the length of the root, by 1.2 times, compared with the control. 


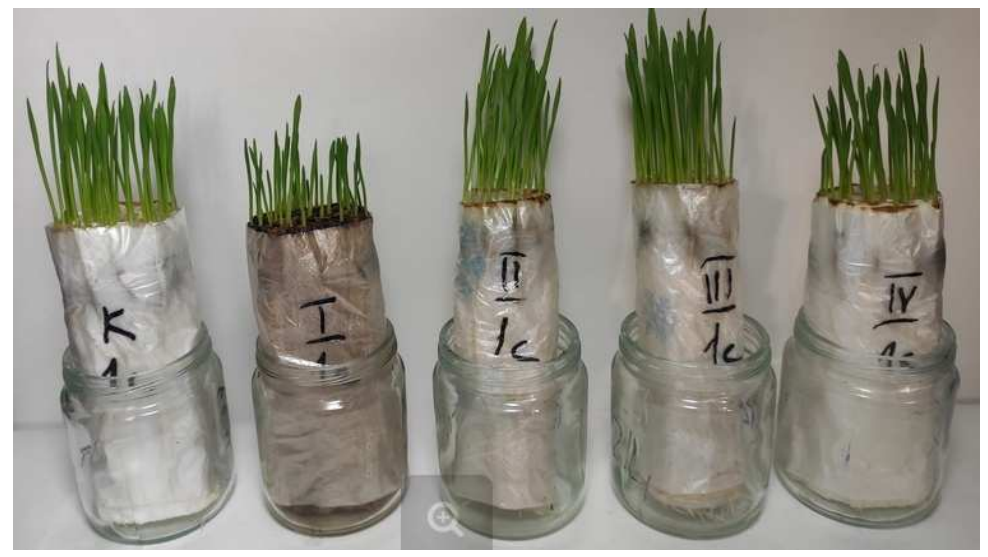

Fig. 5. Influence of solutions of aqueous extract from A. negundo leaf litter on the growth of seeds of Avena sativa $\mathrm{L}$. - the second series of experiments (24-hour infusion).

\section{Conclusion}

Allelopathic substances contained in the leaf litter of $A$. negundo have an inhibitory effect on seed germination and seedling growth of only dicotyledonous plants. The negative effect of water extracts from leaf litter on the germination energy and suppression of seed germination, slowing down of the growth of the cotyledonous knee in radish plants was noted. At the same time, the use of solutions with low concentrations of chemical compounds had a stimulating effect on radish plants.

Monocotyledonous plants, in particular, Avena sativa, exhibit allelopathic resistance to the effects of chemical compounds isolated from the A. negundo leaf litter. In the experiment, the germination of A. sativa seeds decreased only by $14 \%$ compared to control plants, and a slowdown in stem and root growth (1.2 times compared to control) was recorded only at the maximum concentration of an aqueous solution of 24-hour infusion.

In general, a negative allelopathic effect on the germination and development of seedlings of test objects was noted only for solutions with a high concentration of chemical compounds isolated from the A. negundo leaf litter. For the concentrations of extracts taken to be considered close to natural (1:100), no negative effect on the test objects was revealed.

Thus, it was experimentally revealed that the allelopathic effect of A. negundo litter is not a limiting factor for the germination of herbaceous plant seeds in the above-ground cover of the plantation under study.

Acknowledgement. The reported study was carried out in accordance with the NBS-NSC RAS Research Project № 110829-2019-0032 and MBG RAS Research Project № 19-119080590035-9.

\section{References}

1. Yu. K. Vinogradova, S. Ed. Mayorov, L. V. Horun, Black Book of Flora of Central Russia (Geos, Moscow, 2010)

2. L. M. Abramova, Izvestiya Samar. Scient. Center RAS, 14 (1) (2012)

3. Yu. K. Vinogradova et al., The 'Black'-list of invasive species of Russia, Proceedinds of the Materials of the IV Int. Conf., 1-2 Oktober, Kemerovo (2015)

4. Yu. Yu. Dgebuadze, V. G. Petrosian, L. A. Hliap, The most dangerous invasive species in Russia (TOP-100), (KMK, Moscow, 2018) 
5. D. V. Veselkin, D. I. Dubrovin, Russian J. of Biological Invasions, 50 (5) (2019)

6. A. P. Gusev, N. S. Shpilevskaya, D. V. Veselkin, Vestnik VSU, 1 (94) (2017)

7. O. P. Lavrova, D. A. Petrov, E. V. Arjaev, D. Yu. Miroshkina, Allelopathic influence of trees on the herbaceous cover in their undercrown space, Proceedinds of the Materials of the VIII Scientific-practical Conf., Nizhny Novgorod 21 March (2012)

8. O. S. Rafikova, D. I. Dubrovin, Seed Germination of native plants is not reduced in the thickets of invasive Acer negundo, Proceedinds of the Materials of Int. Conf., November 14-15, Perm (2019)

9. E. Rice, Allelopathy (Mir, Moscow, 1978)

10. A. M. Grodzinsky, Bioassays and Biotests (unfinished manuscripts of Academician A.M. Grodzinsky), (Kiev, 2011)

11. Yu. A. Yeryomenko, Industrial Botany, 12 (2012)

12. Yu. A. Yeryomenko, Russin J. of Biological Invasions, 5 (3) (2014).

13. A. P. Moroz, Allelopaphy in Fruit Orchards (Naukova Dumka, Kiev, 1990)

14. N. M. Matveev, Allelopathy as a Factor of the Ecological Environment (Samara, 1994)

15. E. I. Kudriavceva, Yu. Kir. Vinogradova, K. B. Viting, A. M. Kozyreva, A. D.

Nefedova, E. G. Petrash, A. S. Stukalov, A. D. Sheinova, N. M. Reshetnikova, Russian J. of Biological Invasions, 2 (2020) 